\title{
MIRD Commentary: Proposed Name for a Dosimetry Unit Applicable to Deterministic Biological Effects-The Barendsen (Bd)
}

\author{
George Sgouros ${ }^{1}$, Roger W. Howell ${ }^{2}$, Wesley E. Bolch ${ }^{3}$, and Darrell R. Fisher ${ }^{4}$ \\ In collaboration with the MIRD Committee of the SNM: Wesley E. Bolch, A. Bertrand Brill, Darrell R. Fisher, \\ Roger W. Howell, Ruby F. Meredith, George Sgouros (Chair), Barry W. Wessels, and Pat B. Zanzonico \\ ${ }^{1}$ Department of Radiology and Radiological Science, School of Medicine, Johns Hopkins University, Baltimore, Maryland; \\ ${ }^{2}$ Department of Radiology, New Jersey Medical School Cancer Research Center, Newark, New Jersey; ${ }^{3}$ Department of Nuclear and \\ Radiological Engineering, University of Florida, Gainesville, Florida; and ${ }^{4}$ Pacific Northwest National Laboratory, Richland, Washington
}

A good name is better than precious ointment.

Hebrew Ecclesiastes 7:1

The fundamental physical quantity for relating all biologic effects to radiation exposure is the absorbed dose, the energy imparted per unit mass of tissue. Absorbed dose is expressed in units of joules per kilogram $(\mathrm{J} / \mathrm{kg})$ and is given the special name gray (Gy). Exposure to ionizing radiation may cause both deterministic and stochastic biologic effects. To account for the relative effect per unit absorbed dose that has been observed for different types of radiation, the International Commission on Radiological Protection (ICRP) has established radiation weighting factors for stochastic effects. The product of absorbed dose in Gy and the radiation weighting factor is defined as the equivalent dose. Equivalent dose values are designated by a special named unit, the sievert (Sv). Unlike the situation for stochastic effects, no well-defined formalism and associated special named quantities have been widely adopted for deterministic effects. The therapeutic application of radionuclides and, specifically, $\alpha$-particle emitters in nuclear medicine has brought to the forefront the need for a well-defined dosimetry formalism applicable to deterministic effects that is accompanied by corresponding special named quantities. This commentary reviews recent proposals related to this issue and concludes with a recommendation to establish a new named quantity.

Key Words: MIRD; barendsen (Bd); dosimetry

J Nucl Med 2009; 50:485-487

DOI: 10.2967/jnumed.108.057398

$\mathbf{E}$ xposure to ionizing radiation may cause both deterministic and stochastic biologic effects. Deterministic effects

Received Aug. 22, 2008; revision accepted Oct. 9, 2008.

For correspondence or reprints contact: George Sgouros, Department of Radiology and Radiological Science, School of Medicine, Johns Hopkins University, CRB II 4M61, 1550 Orleans St., Baltimore, MD 21231.

E-mail: gsgouros@jhmi.edu

COPYRIGHT @ 2009 by the Society of Nuclear Medicine, Inc. are those that typically occur soon after exposure and that increase in magnitude with increasing doses above a threshold dose level. Examples of such effects include tumor regression, bone marrow suppression, and nephrotoxicity. Stochastic effects of radiation typically occur later after exposure, and the probability but not the magnitude of the effects is dose dependent. A threshold dose level for stochastic effects is generally not assumed. Examples of stochastic effects include cancer induction and genetic changes. Stochastic effects are of concern in diagnostic nuclear medicine, in which the absorbed doses are generally low. Deterministic effects are of concern in therapeutic nuclear medicine, in which the absorbed doses are high and intended to be cytotoxic. Stochastic effects are also possible in the dose ranges in which deterministic effects are manifested.

The fundamental physical quantity for relating all biologic effects to radiation exposure is the absorbed dose, the energy imparted per unit of mass of tissue. The absorbed dose is expressed in the units joules per kilogram $(\mathrm{J} / \mathrm{kg})$ and is given the special name gray (Gy).

\section{STOCHASTIC EFFECTS}

In the realm of stochastic effects, the probability that a particular biologic event will occur after radiation exposure also depends on several other radiologic variables, including the ionization density of the radiation delivered. For example, $\alpha$-particles, because of their high linear energy transfer (LET), yield a greater density of ionization events per unit of distance traveled than do photons and electrons. Thus, $\alpha$-particles have a higher probability of causing DNA damage and a higher probability of causing stochastic effects per unit of absorbed dose. To reflect this greater biologic impact, the International Commission on Radio- 
logical Protection has established the radiation weighting factor, denoted $w_{R}$, to account for the relative effect per unit of absorbed dose that has been observed for different types of radiation. The product of the absorbed dose (expressed in Gy) and the radiation weighting factor $w_{R}$ is defined as the equivalent dose. Equivalent dose values are designated by a special named unit, the sievert (Sv). Accordingly, equivalent dose values may be used directly to assess the relative risk of radiation exposure such that a higher value (expressed in Sv) implies a greater risk of cancer induction. Stochastic effects are generally of concern in the context of "low-level" exposures, such as those encountered in occupational, environmental, and diagnostic medical settings.

\section{DETERMINISTIC EFFECTS}

The second category of biologic effects is deterministic effects. As noted earlier, these are biologic effects, such as toxicity or tumor cell killing, whose magnitude depends on absorbed doses above a threshold dose level. Deterministic effects are also sensitive to the ionization density of the radiation. The magnitude of the deterministic effect caused by a given absorbed dose depends on the LET of the particles and on many additional parameters, such as the dose rate, the spatial distribution of the absorbed dose, and tissue radiosensitivity.

Unlike the situation for stochastic effects, no welldefined formalism and associated special named quantities have been widely adopted for deterministic effects. Rather, scientific organizations have recommended that the relative biological effectiveness (RBE) of the high-LET radiation for a specific deterministic effect be used to weight the absorbed dose (1-4). In this context, the RBE is analogous to the weighting factor $w_{R}$ used to define the equivalent dose, except that in this case, the RBE is a measured quantity for a specific deterministic endpoint rather than a value established by a review committee's consensus regarding RBE values for relevant stochastic endpoints. Because no special name has been proposed for absorbed dose values weighted by deterministic RBE values, there has been confusion regarding the appropriate biologically meaningful expression of absorbed dose values related to deterministic effects. This confusion is evident from the occasional publication of articles reporting deterministic biologic effects arising at high-level radiation exposures in which the radiation doses were reported in sieverts.

\section{PROPOSED QUANTITY AND SPECIAL NAMED UNIT FOR DETERMINISTIC EFFECTS}

The therapeutic application of radionuclides, especially $\alpha$-particle emitters in nuclear medicine (5-7), and the advent of proton-beam and other charged particle-beam therapies in radiotherapy $(8,9)$ have highlighted the need for a well-defined dosimetry formalism and accompanying corresponding special named quantities applicable to deterministic effects. Several solutions have been proposed to address this problem. For example, the National Council on Radiation Protection and Measurements and the International Commission on Radiological Protection have proposed the unit gray-equivalent (Gy-Eq) for an RBEweighted absorbed dose (2,3). In 2007, the International Commission on Radiological Protection proposed the use of gray (Gy) (4) as the unit for an RBE-weighted absorbed dose for deterministic biologic effects. In the field of proton-beam therapy, the term "equivalent dose" has been used with the unit gray-equivalent (GyE) or cobalt grayequivalent (CGE) (10-12).

A working group established jointly by the International Atomic Energy Agency (IAEA) and the International Commission on Radiation Units and Measurements (ICRU) to address these issues in the context of ion-beam therapy recently proposed a formalism to resolve the issues of quantities and units used for predicting deterministic effects of ionizing radiation (13). The IAEA-ICRU working group introduced the quantity isoeffective dose $\left(D_{I s o E}\right)$, which was defined as the product of the absorbed dose $(D)$ and an isoeffective weighting factor $\left(w_{I S O E}\right)$. This weighting factor was defined to account for all factors that could influence the clinical deterministic effects associated with a given absorbed dose. In radionuclide therapy, these factors would include but would not be limited to the radiation type, the dose rate (14-18), and the spatial distribution of the absorbed dose (19-21). The reference irradiation condition for determining $w_{I s o E}$ was defined to be photons delivered at 2 Gy per fraction and 5 daily fractions per week, the time-dose fractionation regimen commonly used in externalbeam radiation therapy. The IAEA-ICRU working group recommended that the isoeffective dose be expressed in the unit gray.

Although $w_{I S O E}$ is similar in concept to RBE, it differs in that the reference radiation is well defined and has traditionally been used in therapeutic nuclear medicine as the standard for predicting the likely biologic consequences of a particular absorbed dose. Correspondingly, the MIRD Committee of the SNM recommends that the isoeffective dose formalism be adopted for use in therapeutic nuclear medicine. However, to avoid confusion and to parallel the formalism established for stochastic effects, the MIRD Committee recommends that the isoeffective dose be expressed in a new special named unit, the barendsen (Bd).

The MIRD Committee recommends the use of this special named unit in recognition of the seminal contributions of Gerrit W. Barendsen to the radiobiology of highLET radiation. He is particularly well known for his work on quantifying the biologic effects of radiation as a function of LET (22-44). His findings are prominently displayed in the textbook Radiobiology for the Radiologist (45).

\section{CONCLUSION}

Pending approval by the appropriate national and international agencies, both of these recommendations will be formalized by publication of a MIRD Committee pamphlet. 


\section{REFERENCES}

1. International Commission on Radiological Protection. ICRP Publication 58: RBE for deterministic effects. Ann ICRP. 1989;20:1-57.

2. International Commission on Radiological Protection. ICRP Publication 92: Relative Biological Effectiveness (RBE), Quality Factor $(Q)$, and Radiation Weighting Factor (WR). Stockholm, Sweden: International Commission on Radiological Protection; 2003.

3. National Council on Radiation Protection and Measurements. Radiation Protection Guidance for Activities in Low-Earth Orbit. Bethesda, MD: National Council on Radiation Protection and Measurements; 2000. Report Number 132.

4. The 2007 Recommendations of the International Commission on Radiological Protection. ICRP publication 103. Ann ICRP. 2007;37:1-332.

5. Sgouros G. Alpha-particles for targeted therapy. Adv Drug Deliv Rev. 2008;60: 1402-1406.

6. Mulford DA, Scheinberg DA, Jurcic JG. The promise of targeted $\alpha$-particle therapy. J Nucl Med. 2005;46(suppl 1):199S-204S.

7. Zalutsky MR, Reardon DA, Pozzi OR, Vaidyanathan G, Bigner DD. Targeted alpha-particle radiotherapy with ${ }^{211}$ At-labeled monoclonal antibodies. Nucl Med Biol. 2007;34:779-785.

8. Greco C. Particle therapy in prostate cancer: a review. Prostate Cancer Prostatic Dis. 2007;10:323-330.

9. Pijls-Johannesma M, Grutters JP, Lambin P, Ruysscher DD. Particle therapy in lung cancer: where do we stand? Cancer Treat Rev. 2008;34:259-267.

10. Fitzek MM, Thornton AF, Rabinov JD, et al. Accelerated fractionated proton/ photon irradiation to 90 cobalt gray equivalent for glioblastoma multiforme: results of a phase II prospective trial. J Neurosurg. 1999;91:251-260.

11. Marucci L, Niemierko A, Liebsch NJ, Aboubaker F, Liu MCC, Munzenrider JE. Spinal cord tolerance to high-dose fractionated 3D conformal proton-photon irradiation as evaluated by equivalent uniform dose and dose volume histogram analysis. Int J Radiat Oncol Biol Phys. 2004;59:551-555.

12. Trofimov A, Nguyen PL, Coen JJ, et al. Radiotherapy treatment of early-stage prostate cancer with IMRT and protons: a treatment planning comparison. Int J Radiat Oncol Biol Phys. 2007;69:444-453.

13. Wambersie A, Hendry JH, Andreo P, et al. The RBE issues in ion-beam therapy: conclusions of a joint IAEA/ICRU working group regarding quantities and units. Radiat Prot Dosimetry. 2006;122:463-470.

14. Fowler JF. Radiobiological aspects of low-dose rates in radioimmunotherapy. Int J Radiat Oncol Biol Phys. 1990;18:1261-1269.

15. Fowler JF. The linear-quadratic formula and progress in fractionated radiotherapy. Br J Radiol. 1989;62:679-694.

16. Dale RG. Dose-rate effects in targeted radiotherapy. Phys Med Biol. 1996;41: 1871-1884.

17. Rao DV, Howell RW. Time-dose-fractionation in radioimmunotherapy: implications for selecting radionuclides. J Nucl Med. 1993;34:1801-1810.

18. Howell RW, Goddu SM, Rao DV. Application of the linear-quadratic model to radioimmunotherapy: further support for the advantage of longer-lived radionuclides. J Nucl Med. 1994;35:1861-1869.

19. Niemierko A. Reporting and analyzing dose distributions: a concept of equivalent uniform dose. Med Phys. 1997;24:103-110.

20. Kutcher GJ, Burman C, Brewster L, Goitein M, Mohan R. Histogram reduction method for calculating complication probabilities for three-dimensional treatment planning evaluations. Int J Radiat Oncol Biol Phys. 1991;21: $137-146$.

21. O'Donoghue JA. Implications of nonuniform tumor doses for radioimmunotherapy. J Nucl Med. 1999;40:1337-1341.

22. Barendsen GW, Beusker TLJ. Effects of different ionizing radiations on human cells in tissue culture. 1. Irradiation techniques and dosimetry. Radiat Res. 1960;13:832-840.

23. Barendsen GW, Beusker TLJ, Vergroesen AJ, Budke L. Effects of different ionizing radiations on human cells in tissue culture. 2. Biological experiments. Radiat Res. 1960;13:841-849.
24. Barendsen GW, Vergroesen AJ. Irradiation of human cells in tissue culture with alpha-rays, beta-rays and x-rays [abstract]. Int J Radiat Biol Relat Stud Phys Chem Med. 1960;2:441.

25. Barendsen GW. Dose-survival curves of human cells in tissue culture irradiated with alpha-, beta-, 20-kV. x- and 200-kV x-radiation. Nature. 1962;193:1153-1155.

26. Barendsen GW, Walter HMD, Fowler JF, Bewley DK. Effects of different ionizing radiations on human cells in tissue culture. 3. Experiments with cyclotronaccelerated alpha-particles and deuterons. Radiat Res. 1963;18:106-119.

27. Barendsen GW, Walter HMD. Effects of different ionizing radiations on human cells in tissue culture. 4. Modification of radiation damage. Radiat Res. 1964; 21:314-329.

28. Barendsen GW. Modification of radiation damage by fractionation of dose anoxia + chemical protectors in relation to LET. Ann N Y Acad Sci. 1964;114: 96-114.

29. Barendsen GW. Impairment of the proliferative capacity of human cells in culture by alpha-particles with differing linear-energy transfer. Int J Radiat Biol Relat Stud Phys Chem Med. 1964;8:453-466.

30. Barendsen GW, Koot CJ, Van Kersen GR, Bewley DK, Field SB, Parnell CJ. The effect of oxygen on impairment of the proliferative capacity of human cells in culture by ionizing radiations of different LET. Int J Radiat Biol Relat Stud Phys Chem Med. 1966;10:317-327.

31. Westra A, Barendsen GW. Proliferation characteristics of cultured mammalian cells after irradiation with sparsely and densely ionizing radiations. Int J Radiat Biol Relat Stud Phys Chem Med. 1966;11:477-485.

32. Barendsen GW. Responses of cultured cells, tumours, and normal tissue to radiations of different linear energy transfer. Curr Top Radiat Res Q. 1968;4:293-356.

33. Barendsen GW, Broerse JJ. Experimental radiotherapy of a rat rhabdomyosarcoma with $15 \mathrm{MeV}$ neutrons and $300 \mathrm{kV}$ x-rays. 1. Effects of single exposures. Eur J Cancer. 1969;5:373-391.

34. Barendsen GW, Broerse JJ. Experimental radiotherapy of a rat rhabdomyosarcoma with $15 \mathrm{MeV}$ neutrons and $300 \mathrm{kV}$ x-rays. 2. Effects of fractionated treatments, applied 5 times a week for several weeks. Eur J Cancer. 1970;6:89-109.

35. Barendsen GW. Influence of radiation quality on the effectiveness of small doses for induction of reproductive death and chromosome aberrations in mammalian cells. Int J Radiat Biol Relat Stud Phys Chem Med. 1979;36:49-63.

36. Barendsen GW. Dose fractionation, dose rate and iso-effect relationships for normal tissue responses. Int J Radiat Oncol Biol Phys. 1982;8:1981-1997.

37. Barendsen GW. A hypothesis concerning the interaction of DNA double-strand breaks as a mechanism for cell reproductive death as a function of LET [abstract]. Int J Radiat Biol. 1990;58:1046.

38. Barendsen GW. LET dependence of linear and quadratic terms in dose-response relationships for cellular damage: correlations with the dimensions and structures of biological targets. Radiat Prot Dosimetry. 1990;31:235-239.

39. Barendsen GW. Sublethal damage and DNA double strand breaks have similar RBE-LET relationships: evidence and implications. Int J Radiat Biol. 1993;63: 325-330.

40. Barendsen GW. RBE LET relationships for different types of lethal radiation damage in mammalian cells: comparison with DNA DSB and an interpretation of differences in radiosensitivity. Int $J$ Radiat Biol. 1994;66:433-436.

41. Barendsen GW. The relationships between RBE and LET for different types of lethal damage in mammalian cells: biophysical and molecular mechanisms. Radiat Res. 1994;139:257-270.

42. Barendsen GW. RBE-LET relationships for DNA lesions and different types of cellular damage. Radiat Prot Dosimetry. 1994;52:359-362.

43. Barendsen GW. Parameters of linear-quadratic radiation dose-effect relationships: dependence on LET and mechanisms of reproductive cell death. Int $J$ Radiat Biol. 1997;71:649-655.

44. Barendsen GW, Van Bree C, Franken NA. Importance of cell proliferative state and potentially lethal damage repair on radiation effectiveness: implications for combined tumor treatments (review). Int J Oncol. 2001;19:247-256.

45. Hall EJ, Giaccia AJ. Radiobiology for the Radiologist. 6th ed. Philadelphia, PA: JB Lippincott Co.; 2005. 